\title{
Non-Alcoholic Fatty Liver Disease and Cardiovascular Risk
}

\author{
Vijay Laxmi Misra, MD ${ }^{1,2}$, Mouen Khashab, MD ${ }^{1,2}$, and Naga Chalasani, MD ${ }^{1,2}$ \\ ${ }^{1}$ Division of Gastroenterology and Hepatology, Department of Medicine, Indiana University School \\ of Medicine, Indianapolis, IN \\ ${ }^{2}$ Clarian/IU Digestive Diseases Center, Indianapolis, IN
}

\begin{abstract}
Nonalcoholic fatty liver disease (NAFLD) is a very common cause of chronic liver disease in United States. A large proportion of patients with NAFLD have co-existing metabolic syndrome which is a major risk factor for cardiovascular disease. A strong association between NAFLD and cardiovascular disease has been long suspected and recent studies have confirmed that cardiovascular disease is the single most important cause of mortality in these patient population. There is a suggestion that NAFLD may pose cardiovascular risk above and beyond that is conferred by traditional cardiovascular risk factors (e.g., dyslipidemia, diabetes and smoking). Health care providers managing patients with NAFLD should recognize this increased cardiovascular risk and should undertake early aggressive risk factor modification.
\end{abstract}

\section{Introduction}

More than $65 \%$ of Americans are either overweight or obese. [1] Excess body weight predisposes individuals to chronic diseases such as coronary artery disease, diabetes and nonalcoholic fatty liver disease (NAFLD). The NAFLD is one of the most common causes of chronic liver disease in the United States. It is histologically characterized by the presence of macrovesicular steatosis but occurs in the absence of excessive alcohol consumption. Its histological spectrum includes simple steatosis and steatohepatitis (NASH). The latter presentation can progress to cirrhosis in 15-20\% of subjects over the course of ensuing 10-15 years. [2] As patients with NAFLD are enriched with risk factors known to cause and exacerbate atherosclerosis, it has been suspected that individuals with NAFLD are at heightened risk for cardiovascular disease.[3]

\section{Cardiovascular risk factors in patients with NAFLD}

Conventional risk factor increasing CVD include age, hypertension, diabetes, physical inactivity, smoking, hyperlipidemia, metabolic syndrome and diet. New and novel risk factors for cardiovascular disease include markers for inflammation (e.g., hsCRP, lipoprotein(a), homocysteine), markers of fibrinolytic and hemostatic function (e.g., fibrinogen, tissue plasminogen activator (t-PA), and plasminogen activator inhibitor 1 (PAI-1) antigens), and more recently NAFLD itself. [4-7] Recent data suggest that many of these newer and novel risk factors are also associated with NAFLD (vide infra). The common denominator for both diseases i.e. NAFLD and cardiovascular disease is obesity related metabolic syndrome and it is increasing virtually in all age groups in the United States. [8-10]

Author for correspondence: Naga Chalasani, MD, Professor of Medicine, Indiana University School of Medicine, 1050 Wishard Boulevard RG 4100, Indianapolis, IN 46202, Tel (317) 278-0414, Fax (317) 278-1949, nchalasa@iupui.edu. 
Several studies have shown that patients with NAFLD are heavily enriched with many components of the metabolic syndrome (Table 1). In a cross-sectional study of 876 Taiwanese subjects, $74 \%$ of subjects with the metabolic syndrome had ultrasound evidence of NAFLD confirmed by ultrasound, and hypertriglyceridemia, hyperglycemia, and increased waist circumference were independently associated with the presence of NAFLD.[11] A group from Italy reported increased prevalence of coronary ( $23 \%$ vs. $15.5 \%)$, cerebrovascular $(17.2 \%$ vs. $10.2 \%)$ and peripheral vascular disease $(12.8 \%$ vs. $7 \%$ ) in people with type 2 diabetes and NAFLD as compared to diabetic patients without NAFLD.[12] It has recently been suggested that NAFLD might be an independent risk factor for cardiovascular disease. [6]

\section{NAFLD and surrogate markers of cardiovascular disease}

Several recent studies have shown that adults and children with NAFLD are enriched with risk factors that are generally accepted as surrogates for the risk of cardiovascular disease. Various surrogates used in clinical studies include Framingham Risk Score (consisting age, gender, hypertension, smoking, and hyperlipidemia), carotid artery intima-media thickness, hsCRP, atheroma formation, mediastinal fat pad, endothelial dysfunction and coronary calcium scores (Table 1).

In a cross-sectional population-based study (NHAHES 3), Ioannou et al., compared the 10year risk of cardiovascular events based on the Framingham risk score (FRS) in individuals with normal and elevated ALT activity (> 43 IU/L).[13] After excluding viral hepatitis and excessive alcohol consumption, individuals with elevated ALT had significantly higher FRS than those with normal ALT.[13] A Turkish study in 92 consecutive patients who underwent coronary angiogram for acute coronary syndrome found that NAFLD independently increased the risk for significant coronary artery disease, as documented by coronary angiogram; this was despite controlling for other risk factors .[14] An Italian pediatric study showed that obese children with NAFLD diagnosed by ultrasound had significantly increased carotid artery intima-media thickness (IMT) compared to obese children without NAFLD and lean children. [15] This was confirmed in a subsequent case-control study that showed that biopsy-proven NAFLD ( $n=150)$ had significantly higher prevalence of cardiovascular risk factors than age, gender and BMI-matched children without NAFLD $(n=150)$.[5] Other cross-sectional studies have also documented that patients with NAFLD have significantly greater carotid artery wall thickness than those without NAFLD. [16-18] A large population-based study also suggest premature atherosclerosis in patients with NAFLD.[19]

\section{Cardiovascular morbidity and mortality in NAFLD: Longitudinal studies}

In addition to increased prevalence of cardiovascular risk factors and surrogate markers of atherosclerosis and cardiac events, several recent longitudinal studies have actually shown that cardiovascular disease is one of the most important causes of morbidity and mortality in patients with NAFLD. In a study consisting of 132 patients with biopsy proven NAFLD followed for 18 years, cardiovascular disease was the second most common cause of deaths after all of the cancers combined.[20] In a population-based Olmsted county study, the overall mortality of 420 NAFLD patients was significantly increased over a mean follow-up of 7.6 years compared to general population and cardiovascular disease was among the most common causes of death.[21] Another Swedish study consisting of 129 patients with NAFLD showed that patients with NASH had higher incidence of cardiovascular mortality compared to reference population.[22] A population-based study of 980 NAFLD patients and 6,594 controls followed long term (mean:8.7 yrs [range 0.05-11.7 yrs]) showed that NAFLD patients had significantly increased all-cause mortality and cardiovascular mortality, especially in the 4554 years age group.[24] More recently, another study that linked NHANES III participants to 
follow-up mortality data showed that cardiovascular disease was the leading cause of death in patients with NAFLD.[25]

\section{NAFLD, inflammatory markers, thrombogenic factors, adipocytokines and cardiovascular risk}

Besides the traditional risk factors such as diabetes and hypertension, it is now recognized that cardiovascular disease and metabolic syndrome involve a chronic inflammatory process and impairment in the hemostatic or prothrombotic mechanisms.[3] Recent studies showed high sensitivity of the C-reactive protein (CRP) to predict cardiovascular events.[3] Hemostatic factors associated with increased cardiovascularc risk include plasminogen activator inhibitor-1 (PAI-1), tissue plasminogen activator (tPA), von Willebrand factor, and fibrinogen. The Edinburg Artery Study showed that patients with metabolic syndrome $(n=264)$ had significantly higher levels of fibrinogen, tPA, e-Selectin, CRP, ICAM, and IL-6 compared to patients without metabolic syndrome $(n=498)$.[26] More importantly, in a recent study of healthy non-smoking volunteers, plasma CRP, fibrinogen, $\mathrm{v}-\mathrm{WF}$ and plasminogen activator inhibitor- 1 (PAI-1) activity levels were markedly higher in subjects with hepatic steatosis than in those without, even after controlling for other confounders such as age, BMI, blood pressure, insulin resistance and triglyceride levels.[27] Recently, IL-6 and CRP have been shown to correlate with higher degrees of fibrosis and inflammation (i.e. NASH) in patients with NAFLD.[28] Therefore, NAFLD/NASH should be considered a chronic inflammatory condition which could add further atherogenic stimuli to the already proinflammatory status conferred by the metabolic syndrome.[29,30] In both humans and rodents, adipose tissue macrophages accumulate in adipose tissue with increasing body weight and their quantity correlates with measures of insulin resistance.[31] In obese subjects, adipose tissues macrophages content is higher in visceral than subcutaneous adipose tissue, consistent with the hypothesis that visceral fat plays a more prominent role in insulin resistance.[31] These macrophages are a prominent source of proinflammatory cytokines such as TNF- $\alpha$. This inflammatory cytokine causes a decrease in the level of adiponectin in obesity. [32] Decreased plasma levels of adiponectin, an adipose-secreted adipocytokine with antiatherogenic properties may represent another possible mechanism linking NAFLD and vascular disease. [33]

\section{Therapeutic approach to reducing cardiovascular risk}

Some of the treatments aimed at improving NAFLD are also beneficial in improving cardiovascular risk profile (weight reduction, better control of diabetes, insulin sensitizers), whereas management of co-morbidities such as hypertension and dyslipidemia are not expected to liver condition but are critical to reducing cardiovascular morbidity and mortality.

\section{Weight reduction}

It is generally recommended that initial weight loss target for improving liver histology is $10 \%$ of baseline body weight and it should proceed at a rate of 1-2 pounds per week.[3] Rapid weight fluctuations should be avoided and patients should explicitly be instructed to minimize sudden gain of significant body weight as it may worsen hepatic histology. A recent Swedish study found that $10 \%$ increase in body weight achieved by indulging in two fast food meals per day increased ALT levels from an average of 22 to $97 \mathrm{U} / \mathrm{L}$, and hepatic triglyceride content from 1.1 to $2.8 \%$,, measured by nuclear magnetic resonance spectroscopy.[35]

Among pharmacological agents for weight loss, Rimonabant, a selective CB1 endocannabinoid receptor antagonist, is effective in promoting weight loss and improving metabolic syndrome in obese patients.[36] A study showed that Rimonabant $20 \mathrm{mg}$, combined with a hypocaloric 
diet over 1 year, promoted significant decrease in body weight and waist circumference, and cardiovascular risk factors.[37] This medication is not yet approved by the United States FDA. Two multicenter trials have been begun to evaluate Rimonabant but it will be several years before their results become available. It is noteworthy that CB1 receptors are receiving significant attention as a therapeutic target due to their ubiquitous presence in various organs and due to the availability of its antagonists.[38] Exenatide used to treat type 2 diabetes leads to weight loss in addition to glycemic control. Its utility in NAFLD is unknown and recent reports of rare but serious episodes of acute pancreatitis argue against empiric use of this compound to treat NASH. [39] Orlistat, a reversible inhibitor of gastric and pancreatic lipase, may promote weight loss in selected patients but it does not seem to offer any therapeutic benefit beyond that is conferred by the weight loss. [40].

Over the last several years, various forms of laparoscopic weight-loss surgery have become popular. The commonly performed foregut bariatric surgical procedures include roux-en-Y gastric bypass, adjustable gastric banding, gastroplasty and sleeve gastrectomy. Liver histology improves following foregut bariatric surgery in most patients with a very minimal risk of worsening.[41,42] In a recent meta-analysis consisting of 15 studies and 766 paired liver biopsies, Mummadi et al., showed that all components of NAFLD showed significant improvement following foregut bariatric surgery.[42] The impact of bariatric surgery on metabolic syndrome was assessed in a retrospective study in Olmsted County which showed that the number of patients with metabolic syndrome during the follow-up was significantly lower in the surgical group compared to the nonsurgical group (29\% vs $75 \%$ ). A relative risk reduction of 0.59 (95\% CI, 0.48-0.67; $\mathrm{P}<.001$ ) was observed in terms of metabolic syndrome in patients who underwent bariatric surgery.[43] Another study which was prospective but with shorter follow up showed that bariatric surgery reduced 10-year cardiovascular risk reduced from $6.7 \%$ at baseline to $5.2 \%$ at 12 months following the surgery. [44] Although no specific studies were conducted to show if sustained and significant weight reduction would improve cardiovascular outcome in addition to liver histology in patients with NAFLD, there are no reasons to believe why it would not be the case.

\section{Lipid lowering agents}

For cardiovascular risk reduction, ATP III guidelines recommend that LDL cholesterol should be maintained below $100 \mathrm{mg} / \mathrm{dL}$ in subjects with known coronary artery disease or those who are at high risk for coronary artery disease (e.g., type2 diabetics).[3] As patients with NAFLD are heavily enriched with cardiac risk factors and cardiovascular morbidity and mortality is such a dominant issue, their dyslipidemia should be aggressively managed. However, the package inserts for various statins discourage their use in individuals with active liver disease. Over the last 5 years, many studies have consistently shown that statins are very safe in patients with different types of chronic liver disease including nonalcoholic fatty liver.[45-47] Lewis and colleagues have recently reported the results of their double-blind, placebo-controlled, multicenter study of high-dose pravastatin $(80 \mathrm{mg} /$ day $)$ to treat dyslipidemia in patients with chronic liver disease. Compared to placebo, patients receiving high-dose pravastatin over the course of 36 weeks not only did not have increased frequency of adverse events but there was a significant reduction in the mean ALT value.[48] Additionally, statins have known antiinflammatory effects and there are several small studies showing that they may actually improve hepatic histology in patients with NASH.[49,50] Based on these emerging data, it is safe to conclude that statins are exceptionally safe in patients with NAFLD and should be prescribed to treat dyslipidemia in eligible patients with NAFLD. 


\section{Conclusion}

Patients with NAFLD have very high prevalence of cardiac risk factors and several recent studies have shown that cardiovascular morbidity and mortality are in fact more important than hepatic adverse events in patient population. Healthcare providers should recognize this heightened cardiovascular risk. Patients should be educated as it is our experience that they become singularly focused on liver enzymes and ignore more important cardiovascular health. Weight loss and optimal management of diabetes and dyslipidemia would improve hepatic histology and also improve cardiovascular morbidity. Many recent studies have shown that statins are safe in patients with chronic liver disease and thus they should not be avoided in NAFLD patients with dyslipidemia.

\section{Acknowledgements}

This work in part was supported by PHS grant K24 DK072101 (to N.C.). Dr. Chalasani has served as a paid consultant to Atherogenics, Pfizer, Takeda, Advanced Life Sciences, Karo-Bio, Metabasis and Eli-Lilly over the past 12-months. He has agreements to conduct clinical trials related to fatty liver disease with Debiovision, Sanofi-Aventis, Pfizer and Gilead.

\section{References and Recommended Reading}

Papers of particular interest, published recently, have been highlighted as:

- Of importance

•• Of major importance

1. NIDDK. Understanding adult obesity. [Accessed September 2008]. Available at http://win.niddk.nih.gov/publications/understanding.htm

2. Cheung O, Kapoor A, Puri P, et al. The impact of fat distribution on the severity of nonalcoholic fatty liver disease and metabolic syndrome. Hepatology 2007;46:1091-1100. [PubMed: 17610277]

3. Expert Panel on Detection, Evaluation, and Treatment of High Blood Cholesterol in Adults. Executive Summary of the Third Report of the National Cholesterol Education Program (NCEP) Expert Panel on Detection, Evaluation, and Treatment of High Blood Cholesterol in Adults (Adult Treatment Panel III). JAMA 2001;285:2486-2497. [PubMed: 11368702]

4. Galassi A, Reynolds K, He J. Metabolic Syndrome and Risk of Cardiovascular Disease: A MetaAnalysis. Am J Med 2006;119:812-819. [PubMed: 17000207]

5. Schwimmer JB, Pardee PE, Lavine JE, et al. Cardiovascular Risk Factors and the Metabolic Syndrome in Pediatric Nonalcoholic Fatty Liver Disease. Circulation 2008;118:277-283.283 [PubMed: 18591439]This large case-control study showed high prevalence of the metabolic syndrome in overweight and obese children with NAFLD.

6. Targher G, Arcaro G. Non-alcoholic fatty liver disease and increased risk of cardiovascular disease. Atherosclerosis 2007;191:235-240. [PubMed: 16970951]

7. Jeppesen JA, Hansen TW, Olsen MH, et al. C-reactive protein, insulin resistance and risk of cardiovascular disease: a population-based study. European Journal of Cardiovascular Prevention \& Rehabilitation. 2008In press

8. Weiss R, Dziura J, Burgert TS. Obesity and the Metabolic Syndrome in Children and Adolescents. NEJM 2004;350:2362-2374. [PubMed: 15175438]

9. Hamaguchi M, Kojima T, Takeda N, et al. The metabolic syndrome as a predictor of nonalcoholic fatty liver disease. Ann Intern Med 2005;143:722-728. [PubMed: 16287793]

10. Okosun IS, Chandra KM, Boev A, et al. Abdominal adiposity in U.S. adults: prevalence and trends, 1960-2000. Prev Med 2004;39:197-206. [PubMed: 15208003]

11. Tsai C-H, Li T-C, Lin C-C. Metabolic Syndrome as a Risk Factor for Nonalcoholic Fatty Liver Disease. South Med J 2008;101:900-905. [PubMed: 18708987] 
12. Targher G, Bertolini L, Padovani R, et al. Prevalence of Nonalcoholic Fatty Liver Disease and Its Association with Cardiovascular Disease among Type 2 Diabetic Patients. Diabetes Care 2007;30:1212-1218. [PubMed: 17277038]

13. Ioannou GS, Weiss NS, Boyko EJ, et al. Elevated serum alanine aminotransferase activity and calculated risk of coronary heart disease in the United States. Hepatology 2006;43:1145-1151.1151 [PubMed: 16628637]This NHANESIII based study showed that individuals with unexplained elevations in ALT (i.e. suspected NAFLD) have significantly higher Framingham Risk Scores and this portrays heightened cardiovascular risk over the next 10-year period.

14. Ua A, Sa T, Sa B, et al. Association between nonalcoholic fatty liver disease and coronary artery disease. Coronary Artery Dis 2007;18:433-436.

15. Pacifico L, Cantisani V, Ricci P, et al. Nonalcoholic fatty liver disease and carotid atherosclerosis in children. Pediatr Res 2008;63:423-427. [PubMed: 18356751]

16. Brea A, Mosquera D, Martin E, et al. Nonalcoholic Fatty Liver Disease Is Associated With Carotid Atherosclerosis: A Case-Control Study. Arterioscler Thromb Vasc Biol 2005;25:1045-1050.

[PubMed: 15731489]

17. Targher G, Bertolini L, Padovani R, et al. Relation of Nonalcoholic Hepatic Steatosis to Early Carotid Atherosclerosis in Healthy Men: Role of visceral fat accumulation. Diabetes Care 2004;27:24982500. [PubMed: 15451925]

18. Sookoian S, Pirola CJ. Non-alcoholic fatty liver disease is strongly associated with carotid atherosclerosis: A systematic review. J Hepatol 2008;49:600-607. [PubMed: 18672311]

19. Volzke H, Robinson DM, Kleine V, et al. Hepatic steatosis is associated with an increased risk of carotid atherosclerosis. World Journal of Gastroenterology 2005;11:1848-1853. [PubMed: 15793879]

20. Matteoni CA, Younossi ZM, Gramlich T, et al. Nonalcoholic fatty liver disease: a spectrum of clinical and pathological severity. Gastroenterology 1999;116:1413-1419. [PubMed: 10348825]

21. Adams LA, Lymp JF, St. Sauver J, et al. The Natural History of Nonalcoholic Fatty Liver Disease: A Population-Based Cohort Study. Gastroenterology 2005;129:113-121. [PubMed: 16012941]

22. Ekstedt M, Franzén LE, Mathiesen UL, et al. Long-term follow-up of patients with NAFLD and elevated liver enzymes. Hepatology 2006;44:865-873.873 [PubMed: 17006923]This long term clinical and histological follow-up study demonstrated the natural course of NAFLD based on histological spectrum.

23. Aygun C, Kocaman O, Sahin T, et al. Evaluation of metabolic syndrome frequency and carotid artery intima-media thickness as risk factors for atherosclerosis in patients with nonalcoholic fatty liver disease. Dig Dis Sci 2008;53:1352-1357. [PubMed: 17939039]

24. Dunn W, Xu R, Wingard DL, et al. Suspected Nonalcoholic Fatty Liver Disease and Mortality Risk in a Population-Based Cohort Study. Am J Gastroenterol 2008;103:2263-2271. [PubMed: 18684196]

25. Ong JP, Pitts A, Younossi ZM. Increased overall mortality and liver-related mortality in non-alcoholic fatty liver disease. J Hepatol 2008;49:608-612. [PubMed: 18682312]

26. Wild SH, Byrne CD, Tzoulaki I, et al. Metabolic syndrome, haemostatic and inflammatory markers, cerebrovascular and peripheral arterial disease: The Edinburgh Artery Study. Atherosclerosis. 2008Accepted, in Press

27. Targher G, Bertolini L, Zoppini G, et al. Increased plasma markers of inflammation and endothelial dysfunction and their association with microvascular complications in Type1 diabetic patients without clinically manifest macroangiopathy. Diabet Med 2005;22:999-1004. [PubMed: 16026364]

28. Wieckowska A, Papouchado BG, Li Z, et al. Increased hepatic and circulating interleukin-6 levels in human nonalcoholic steatohepatitis. Am J Gastroenterol 2008;103:1372-1379. [PubMed: 18510618]

29. Moller DE, Kaufman KD. Metabolic Syndrome: A Clinical and Molecular Perspective. Annu Rev Med 2005;56:45-62. [PubMed: 15660501]

30. Eckel RH, Grundy SM, Zimmet PZ. The metabolic syndrome. Lancet 2005;365:1415-1428. [PubMed: 15836891]

31. Lumeng CN, Deyoung SM, Saltiel AR. Macrophages block insulin action in adipocytes by altering expression of signaling and glucose transport proteins. Am J Physiol Endocrinol Metab 2007;292:166-174. 
32. Hector J, Schwarzloh B, Goehring J, et al. TNF- $\alpha$ Alters Visfatin and Adiponectin Levels in Human Fat. Horm Metab Res 2007;39:250-255. [PubMed: 17447161]

33. Chandran M, Phillips SA, Ciaraldi T, Henry RR. Adiponectin: More Than Just Another Fat Cell Hormone? Diabetes Care 2003;26:2442-2450. [PubMed: 12882876]

34. Huang MA, Greenson JK, Chao CK, et al. One-Year Intense Nutritional Counseling Results in Histological Improvement in Patients with Non-Alcoholic Steatohepatitis: A Pilot Study. Am J Gastroenterol 2005;100:1072-1081. [PubMed: 15842581]

35. Kechagias S, Ernersson A, Dahlqvist O, et al. Fast-food-based hyperalimentation can induce rapid and profound elevation of serum alanine aminotransferase in healthy subjects. Gut 2008;57:649-654. [PubMed: 18276725]

36. Boyd ST, Fremming BA. Rimonabant-A Selective CB1 Antagonist. Ann Pharmacother 2005;39:684690. [PubMed: 15755787]

37. Van Gaal LF, Rissanen AM, Scheen AJ, et al. Effects of the cannabinoid-1 receptor blocker rimonabant on weight reduction and cardiovascular risk factors in overweight patients: 1-year experience from the RIO-Europe study. Lancet 2005;365:1389-1397. [PubMed: 15836887]

38. Mallat A, Lotersztajn S. Endocannabinoids and Liver Disease. I. Endocannabinoids and their receptors in the liver. Am J Physiol Gastrointest Liver Physiol 2008;294:9-12.

39. Buse JB, Klonoff DC, Nielsen LL, et al. Metabolic effects of two years of exenatide treatment on diabetes, obesity, and hepatic biomarkers in patients with type 2 diabetes: An interim analysis of data from the open-label, uncontrolled extension of three double-blind, placebo-controlled trials. Clin Ther 2007;29:139-153. [PubMed: 17379054]

40. Torgerson JS, Hauptman J, Boldrin MN, Sjostrom L. XENical in the Prevention of Diabetes in Obese Subjects (XENDOS) Study: A randomized study of orlistat as an adjunct to lifestyle changes for the prevention of type 2 diabetes in obese patients. Diabetes Care 2004;27:155-161. [PubMed: 14693982]

41. Furuya CK Jr, de Oliveira CP, de Mello ES, et al. Effects of bariatric surgery on nonalcoholic fatty liver disease: preliminary findings after 2 years. J Gastroenterol Hepatol 2007;22:510-514. [PubMed: 17376042]

42. Mummadi R, Kasturi K, Chennareddygari S, Sood G. Effect of Bariatric Surgery on Nonalcoholic Fatty Liver Disease (NAFLD): Systemic Review and Metaanalysis. Clinical Gastroenterology and Hepatology. 2008In Press accepted manuscript

43. Batsis JA, Romero-Corral AA, Collazo-Clavell ML, et al. Effect of Bariatric Surgery on the Metabolic Syndrome: A Population-Based, Long-term Controlled Study. Mayo Clin Proc 2008;83:897-906.906 [PubMed: 18674474]The study provided long term follow up of patients after bariatric surgery in a population based cohort.

44. Arterburn D, Schauer D, Wise R, et al. Change in Predicted 10-Year Cardiovascular Risk Following Laparoscopic Roux-en-Y Gastric Bypass Surgery. Obesity Surgery. 2008 August; In press accepted manuscript

45. Chalasani N, Aljadhey H, Kesterson J, et al. Patients with elevated liver enzymes are not at higher risk for statin hepatotoxicity. Gastroenterology 2004;126:1287-1292. [PubMed: 15131789]

46. Vuppalanchi R, Teal E, Chalasani N. Patients with Elevated Baseline Liver Enzymes Do Not Have Higher Frequency of Hepatotoxicity from Lovastatin than Those with Normal Baseline Liver Enzymes. Am J Med Sci 2005;329:62-65. [PubMed: 15711421]

47. Browning J. Statins and hepatic steatosis: Perspectives from the Dallas Heart Study. Hepatology 2006;44:466-471. [PubMed: 16871575]

48. Lewis JH, Mortensen ME, Zweig S, et al. Efficacy and safety of high-dose pravastatin in hypercholesterolemic patients with well-compensated chronic liver disease: Results of a prospective, randomized, double-blind, placebo-controlled, multicenter trial. Hepatology 2007;46:14531463.1463 [PubMed: 17668878]Well designed, prospective study showing efficacy and safety of statins in chronic liver disease patients.

49. Albert MA, Danielson E, Rifai N, et al. Effect of Statin Therapy on C-Reactive Protein Levels: The Pravastatin Inflammation/CRP Evaluation (PRINCE): A Randomized Trial and Cohort Study. JAMA 2001;286:64-70. [PubMed: 11434828] 
50. Argo C, Loria P, Caldwell SH, Lonardo A. Statins in liver disease: A molehill, an iceberg, or neither? Hepatology 2008;48:662-669. [PubMed: 18666246]

51. Marchesini G, Forlani G, Cerrelli F, et al. Nonalcoholic fatty liver, steatohepatitis, and the metabolic syndrome. Hepatology 2003;37:917-923. [PubMed: 12668987]

52. Perseghin GL, Cobelli F, Esposito A, et al. Increased mediastinal fat and impaired left ventricular energy metabolism in young men with newly found fatty liver. Hepatology 2008;47:51-58. [PubMed: 17955548]

53. Senturk O, Kocaman O, Hulagu S, et al. Endothelial dysfunction in Turkish patients with nonalcoholic fatty liver disease. Internal Medicine Journal 2008;38:183-189. [PubMed: 17725609]

54. Yoneda M, Mawatari H, Fujita K, et al. High-sensitivity C-reactive protein is an independent clinical feature of nonalcoholic steatohepatitis (NASH) and also of the severity of fibrosis in NASH. J Gastroenterol 2007;42:573-582. [PubMed: 17653654] 
Table 1

Cardiovascular disease risk factors and nonalcoholic fatty liver disease

Higher prevalence of traditional cardiovascular risk factors

Obesity

Type2 diabetes
Tsai et al. 2008[11]

Ox-LDL

Metabolic Syndrome

Schwimmer et al. 2008[5]

Higher prevalence of surrogate markers of CVD

\begin{tabular}{|l|l}
\hline Increased pericardial fat pad & Perseghin et al. 2008[52]
\end{tabular}

\begin{tabular}{|l|l}
\hline Endothelial dysfunction & Senturk et al. 2008[53]
\end{tabular}

\begin{tabular}{|l|l}
\hline Framingham Risk Score & Ioannou et al. 2006[13]
\end{tabular}

\begin{tabular}{l|l}
\hline Carotid intima media thickness & Targher et al. 2004[17]
\end{tabular}

Brea et al. 2005[16]

Volzke et al. 2005[19]

Pacifico et al. 2008[15]

hsCRP

Yoneda et al. 2007[54] 
Table 2

Longitudinal studies assessing cardiovascular mortality in nonalcoholic fatty liver disease

\begin{tabular}{|c|c|c|c|c|}
\hline Author & $\mathbf{N}$ & $\begin{array}{l}\text { NAFLD } \\
\text { diagnosis }\end{array}$ & $\underset{(\text { years })}{\mathbf{F} / \mathbf{U}}$ & Comments \\
\hline Matteoni et al.[20] & 132 & Liver biopsy & 18 & $\begin{array}{l}\text { Cardiovascular disease and liver disease are the two } \\
\text { most common causes of death }(\sim 11 \%)\end{array}$ \\
\hline Adams et al.[21] & 420 & $\begin{array}{l}\text { Clinical }+ \\
\text { imaging } \pm \\
\text { biopsy }\end{array}$ & 8 & $\begin{array}{l}\text { Cardiovascular disease was the most common cause } \\
\text { of death }\end{array}$ \\
\hline Ekstedt et al.[22] & 129 & Liver biopsy & 13.7 & $\begin{array}{l}\text { Cardiovascular disease caused significantly more } \\
\text { deaths than liver disease (15.5\% vs. } 2.8 \%)\end{array}$ \\
\hline Dunn et al.[24] & $\begin{array}{l}980 \text { NAFLD } \\
\text { and } 6594 \\
\text { normal } \\
\text { subjects }\end{array}$ & $\begin{array}{l}\text { Unexplained } \\
\text { elevation in } \\
\text { ALT }\end{array}$ & 8.7 & $\begin{array}{l}\text { Suspected NAFLD had significantly higher all-cause } \\
\text { (4.40 95\% CI 1.27-13.23) and cardiovascular mortality } \\
(8.15,95 \% \text { CI } 2.00-33.20) \text { after adjusting for } \\
\text { conventional cardiovascular risk factors. }\end{array}$ \\
\hline Ong et al.[25] & $\begin{array}{c}80 \text { NAFLD } \\
\text { and } 1453 \\
\text { controls }\end{array}$ & $\begin{array}{l}\text { Unexplained } \\
\text { elevation } \\
\text { in ALT }\end{array}$ & 8.7 & $\begin{array}{l}\text { Cardiovascular disease is the most common cause of } \\
\text { death in NAFLD }\end{array}$ \\
\hline
\end{tabular}

